\title{
Differential shrinkage of mesophyll cells in transpiring cotton leaves: implications for static and dynamic pools of water, and for water transport pathways
}

\author{
Martin Canny ${ }^{\mathrm{A}, \mathrm{D}}$, Suan Chin Wong ${ }^{\mathrm{A}}$, Cheng Huang ${ }^{\mathrm{B}}$ and Celia Miller ${ }^{\mathrm{C}}$ \\ APlant Science Division, Research School of Biology, RN Robertson Building, The Australian National University, \\ Canberra, ACT 0200, Australia. \\ ${ }^{B}$ Centre for Advanced Microscopy, The Australian National University, Canberra, ACT 0200, Australia. \\ ${ }^{C}$ Division of Plant Industry, CSIRO, Canberra, ACT 2601, Australia. \\ DCorresponding author. Email: martin.canny@anu.edu.au
}

\begin{abstract}
Shrinkage of palisade cells during transpiration, previously measured for sclerophyllous leaves of Eucalyptus where cells shrank equally, was compared with shrinkage in thin mesophytic leaves of cotton (Gossypium hirsutum L.). Selected vapour pressure differences $(\Delta e)$ from 0.6 to $2.7 \mathrm{kPa}$ were imposed during steady-state photosynthesis and transpiration. Leaves were then cryo-fixed and cryo-planed paradermally, and images obtained with a cryo-scanning electron microscope (CSEM). Diameters of palisade 'cavity cells' within sub-stomatal cavities, and surrounding palisade 'matrix cells' were measured on CSEM images. Cavity and spongy mesophyll cells shrank progressively down to $\Delta e=2.7 \mathrm{kPa}$, while matrix cells remained at the same diameter at all $\Delta e$. Diameters were also measured of cavity and matrix cells quasiequilibrated with relative humidities (RHs) from $100 \%$ to $86 \%$. In leaves quasi-equilibrated with $95 \% \mathrm{RH}$, the cavity cells shrank so much as to be almost unmeasurable, while matrix cells shrank by only $6 \%$. These data suggest that there are two distinct pools of water in cotton leaves: cavity plus spongy mesophyll cells (two-thirds of leaf volume) which easily lose water; and matrix cells (one-third of leaf volume), which retain turgor down to relative water loss $=0.4$, providing structural rigidity to prevent wilting. This phenomenon is probably widespread among mesophytic leaves.
\end{abstract}

Additional keywords: cell interconnections, relative water loss, sites of evaporation, stomatal cavities, transpiration pathway, wilting resistance.

Received 3 August 2011, accepted 15 November 2011, published online 13 December 2011

\section{Introduction}

The pathways by which water moves in a transpiring leaf from the source in the xylem elements to the sites of evaporation have been much debated. Accepting the evidence that the cell wall apoplast is a gel in which the mobility of water is much restricted (Stamm 1964; Canny 1995), we take the view that the water must move through the symplast. A simple view would be that all the leaf cells are connected into a single symplast, that evaporation is from all of them, and that as the water status declines during rapid transpiration, the mesophyll cells should shrink equally.

A study of the changes in mesophyll cell size during transpiration in the sclerophytic leaf of snow gum (Eucalyptus pauciflora Sieb. ex Spreng.) by Canny and Huang (2006) revealed that indeed all mesophyll cells shrank equally to volumes that were dependent on the water status of the leaf. These leaves have a high proportion of cell wall structural material, and have no spongy mesophyll. That study raised the question of how general such changes might be in more mesophytic species. The uniformity of shrinkage suggested that there was a single major pool of water in the E. pauciflora leaf.
In contrast, several studies of mesophytic leaves by two quite different methods have suggested they contain more than one pool of water (Yakir et al. 1989, 1990 for leaves of sunflower (Helianthus annuus L.), ivy (Hedera helix L.) and cotton (Gossypium hirsutum L.); Zwieniecki et al. 2007 for leaves of Quercus, Acer, Liriodendron and Populus). Different pools of water in leaves would most probably be contained in different cell types and, during transpiration, the different types would be expected to shrink to different degrees. The cryoscanning electron microscope (CSEM) enables measurements of the cell diameter preserved at the moment of cryo-fixation. The present paper reports such measurements on leaves of cotton at a range of vapour pressure differences and rates of transpiration, where the cells did not shrink equally.

The location of the pools in different mesophyll types and the different degrees of shrinkage raise questions about the contributions of the different cell types to the transport and evaporation of water. It is reasonable to assume that the magnitude of water movement between one cell and the next depends on the area of the interconnections between the two, and that comparisons of the observed areas of these interconnections 
can indicate the likely pathway of water through the tissues. A qualitative assessment of the interconnections between the mesophyll cells from optical and CSEM images leads to a proposed pattern of water pathways from the xylem to sites of evaporation.

In the paper on Eucalyptus, two states of the leaf cells were considered: (1) the state at a particular time in an attached, intact, transpiring leaf (the steady state); and (2) the state after overnight exposure of a detached leaf to air of known relative humidity (RH) (the quasi-equilibrium state). Comparisons of cell sizes and of relative water losses (RWL) between cotton leaves in these two states (fully turgid and partially dehydrated) were also made in the present paper.

\section{Materials and methods}

\section{Plant material}

Plants of cotton (Gossypium hirsutum L. cv. Deltapine 90) were grown from seed in a glasshouse in natural sunlight. Irradiance at midday was $1400-2000 \mu \mathrm{mol} \mathrm{m}{ }^{-2} \mathrm{~s}^{-1} \mathrm{PAR}$; day temperature $28^{\circ} \mathrm{C}$, night temperature $20^{\circ} \mathrm{C}$; daytime $\mathrm{RH} 40 \%$, night time $\mathrm{RH}$ $80-90 \%$.

\section{Experiment 1: steady-state}

Leaves 4 and 5 of intact 5 -week-old plants were used to impose the selected vapour pressure differences between leaf and air $(\Delta e)$ with a double-sided clamp-on chamber covering $4.9 \mathrm{~cm}^{2}$. Gas flow through the chambers was maintained at the chosen humidity by passing gas through a humidifying bubbler and then through a condenser where the dewpoint was regulated by water circulating from a temperature-controlled water bath. Temperature of the chambers was controlled by water circulated from another temperature-controlled bath, and leaf temperature measured by an infrared thermometer (model M50, Mikron Infrared Inc., Oakland, NJ, USA). The imposed $\Delta e$ were $0.6,1.1,1.3,1.7,2.1$ and $2.7 \mathrm{kPa}$, and a single leaf provided the material for measurement at each $\Delta e$. The irradiance at the leaf surface was $1000 \mu \mathrm{mol} \mathrm{m}^{-2} \mathrm{~s}^{-1}$ PAR. Rates of transpiration $\left(E\right.$, mmol m $\left.\mathrm{m}^{-2} \mathrm{~s}^{-1}\right)$ were calculated from the difference in vapour pressures of outgoing and incoming air multiplied by the flow rate and divided by the leaf area.

To measure the responses of leaf mesophyll cells in the steady state at each $\Delta e$, the position of the leaf chamber on the leaf was outlined with marker pen, the chamber removed and the adaxial surface of that area distinguished by painting it with the pen, so that this surface could be recognised in the microtome. The marked area was immediately cryo-fixed with cryo-pliers cooled to the temperature of liquid nitrogen $\left(\mathrm{LN}_{2}\right)\left(-196^{\circ} \mathrm{C}\right)$, cut out from the leaf and dissected under $\mathrm{LN}_{2}$ into pieces that would fit into cryo-vials. The pieces were stored in the vials at $\mathrm{LN}_{2}$ temperature until processed for measurement.

\section{Experiment 2: quasi-equilibrium state and comparison with standard humidities}

The quasi-equilibrium state is the simpler, having one less variable (absence of water uptake). It is given this name because any system at true equilibrium is dead, but fairly close approaches to equilibrium may be achieved in manageable times. Canny and Huang (2006) provided evidence that Eucalyptus leaf disks exposed to various $\mathrm{RHs}$ reached a near equilibrium state within $24 \mathrm{~h}$, and could recover their full turgor when supplied with water and remained viable. To measure the response of cotton mesophyll cells in the quasi-equilibrium state, following the comparison made for Eucalyptus, as in experiment 3 of Canny and Huang (2006), cotton leaf disks punched out with a 5-mm cork borer from five leaves from each of two plants were equilibrated overnight in very small chambers with air of known RHs (100\%, 98\%, 95\% and 92\%) maintained by saturated salt solutions. The equilibrated disks were frozen in $\mathrm{LN}_{2}$ and stored in cryo-vials at $\mathrm{LN}_{2}$ temperature $\left(-196^{\circ} \mathrm{C}\right)$.

As in Canny and Huang (2006), measurements were also made of the relative water loss $[\mathrm{RWL}=$ (saturated leaf mass $m_{\mathrm{x}}-$ leaf mass $m$ ) $\left.m_{\mathrm{x}}{ }^{-1}\right]$ of disks of cotton leaves after quasiequilibrium with air of a range of RHs. The reasons for preferring relative water loss to relative water content are set out in Canny and Huang (2006). Five detached leaves were brought to full saturation by standing their petioles in water. Five disks from each leaf were weighed to give values of $m_{\mathrm{x}}$, and quasi-equilibrated for $24 \mathrm{~h}$ in the same small chambers and with the same saturated solutions as above, with the addition of one set at $86 \%$ RH. After equilibration, the disks were weighed again to give values of $m$ and the RWL was calculated for each.

Again following Canny and Huang (2006), the maximum mass fraction of water $\left(Q_{\mathrm{x}}=\left(m_{\mathrm{x}}-m_{\mathrm{d}}\right) m_{\mathrm{x}}{ }^{-1}\right.$ where $m_{\mathrm{d}}$ is the dry mass) was measured as the mean of five leaves of the chosen developmental stage from five plants: $Q_{\mathrm{x}}=0.781 \pm 0.008$ $(n=5)$.

\section{Cell connections}

Cryo-fixed material from Experiments 1 and 2 as well as material from similarly grown plants was prepared for optical microscopy.

\section{Microscopy}

\section{Cryo-microscopy}

The frozen leaf pieces were mounted adaxial side up on an Al stub with low-temperature Tissue Tek (Sakura Finetechnical Co., Tokyo, Japan), immediately plunged into $\mathrm{LN}_{2}$, and transferred in $\mathrm{LN}_{2}$ to the chuck of a cryo-microtome (Leica EM UC7, Leica Microsystems, Wetzlar, Germany) and its temperature raised to $-90^{\circ} \mathrm{C}$ in the microtome. Most pieces were planed paradermally from the marked adaxial surface, down to $\sim 50 \mu \mathrm{m}$ depth to expose the transverse faces of mesophyll cells; a few were planed transversely to reveal tissue architecture. The planed pieces were transferred to the CSEM (Cambridge Model 360; Cambridge Instrument Co., Cambridge, UK) and etched at $-90^{\circ} \mathrm{C}$ for a minute or so until the cell outlines were just visible (for details of these procedures see McCully et al. 2009, 2010; McCully and Canny 2011). Specimens were recooled, and then coated with $\mathrm{Au}$ and returned to the column of the microscope for observation. Digital images were recorded and the paradermal faces analysed for cell and tissue dimensions using the program SCION IMAGE Beta ver. 4.02 (Scion Corp. Frederick, MD, USA). Cell area fraction (CAF) was calculated in the paradermal faces, as in (Canny and Huang 2006), as the ratio of the total cell areas to the whole tissue area including intercellular spaces. 

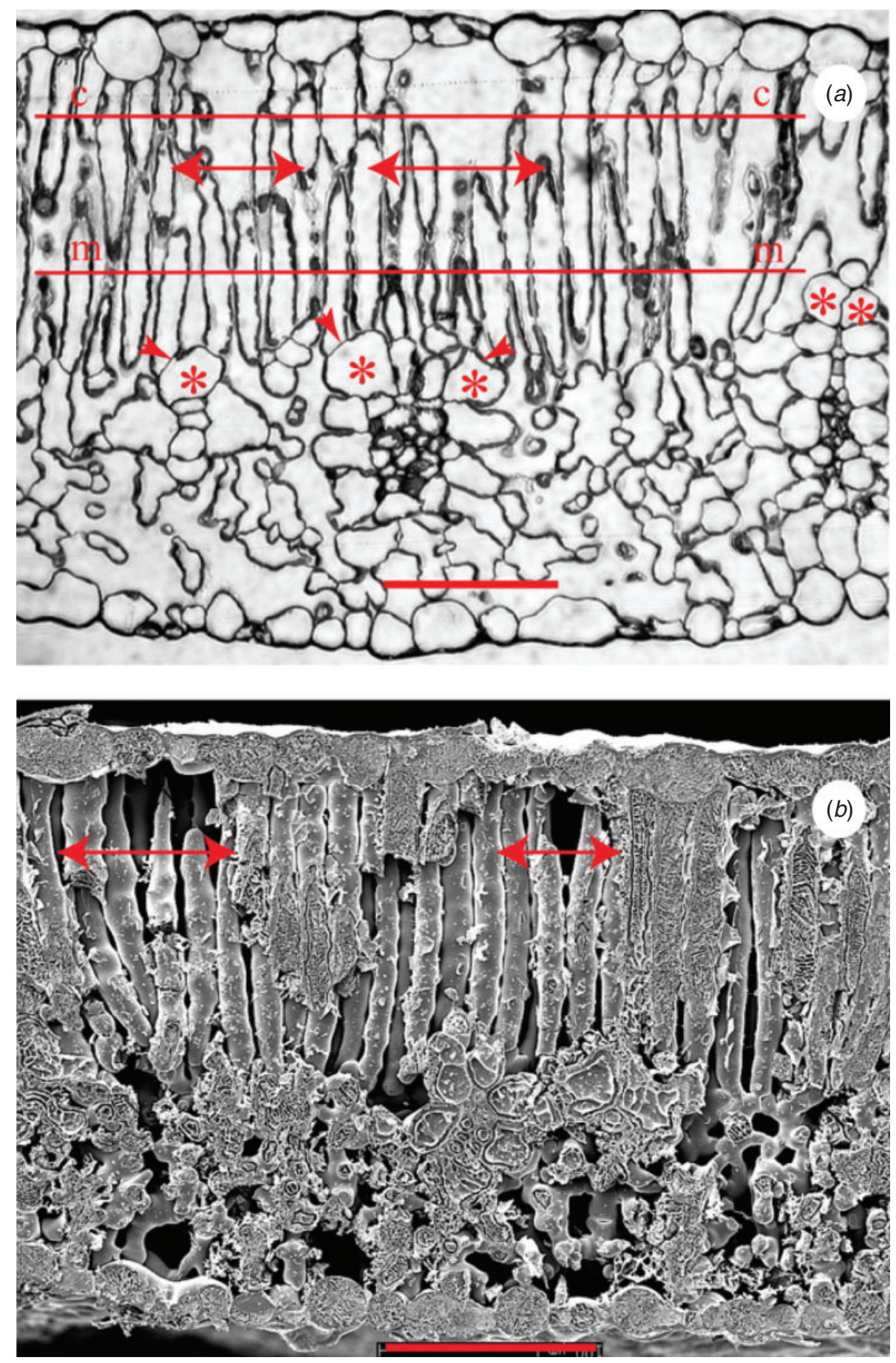

Fig. 1. (a) Transverse $1 \mu \mathrm{m}$-thick optical section of chemically fixed and embedded cotton leaves. (b) Cryofixed and cryo-planed transverse face of a similar leaf. Leaves were at RWL $=0$ for both those chemically fixed and those cryo-fixed, and were typical of those used in the measurements. Substomatal cavities in the palisade tissue are indicated by double arrows. Between these cavities, the palisade cells are closely appressed, with small intercellular spaces. The lines $\mathrm{c}-\mathrm{c}$ and $\mathrm{m}-\mathrm{m}$ in $(a)$ indicate the depths at which paradermal faces of cryo-fixed leaves are compared in Fig. 2. Note the bundle sheath cells (asterisks), and connections between these cells and palisade cells (arrowheads). Because the section is only $1 \mu \mathrm{m}$ thick, some parts of some of the palisade cells are not included in the section, making those cells look shorter than they were in intact leaves. Scale bars $=100 \mu \mathrm{m}$. 
Optical microscopy

Five-millimetre square pieces cut from intact leaves of plants grown as described above were prepared for optical microscopy by fixation in $3 \%$ glutaraldehyde in a $25 \mathrm{mM}$ sodium phosphate buffer at $\mathrm{pH} 7.2$ at room temperature, vacuum infiltrated and held overnight at $4^{\circ} \mathrm{C}$. Dehydration was in an ethanol series and infiltration in LR White 'medium' resin (London Resin Co., Berkshire, UK). Serial transverse and paradermal sections
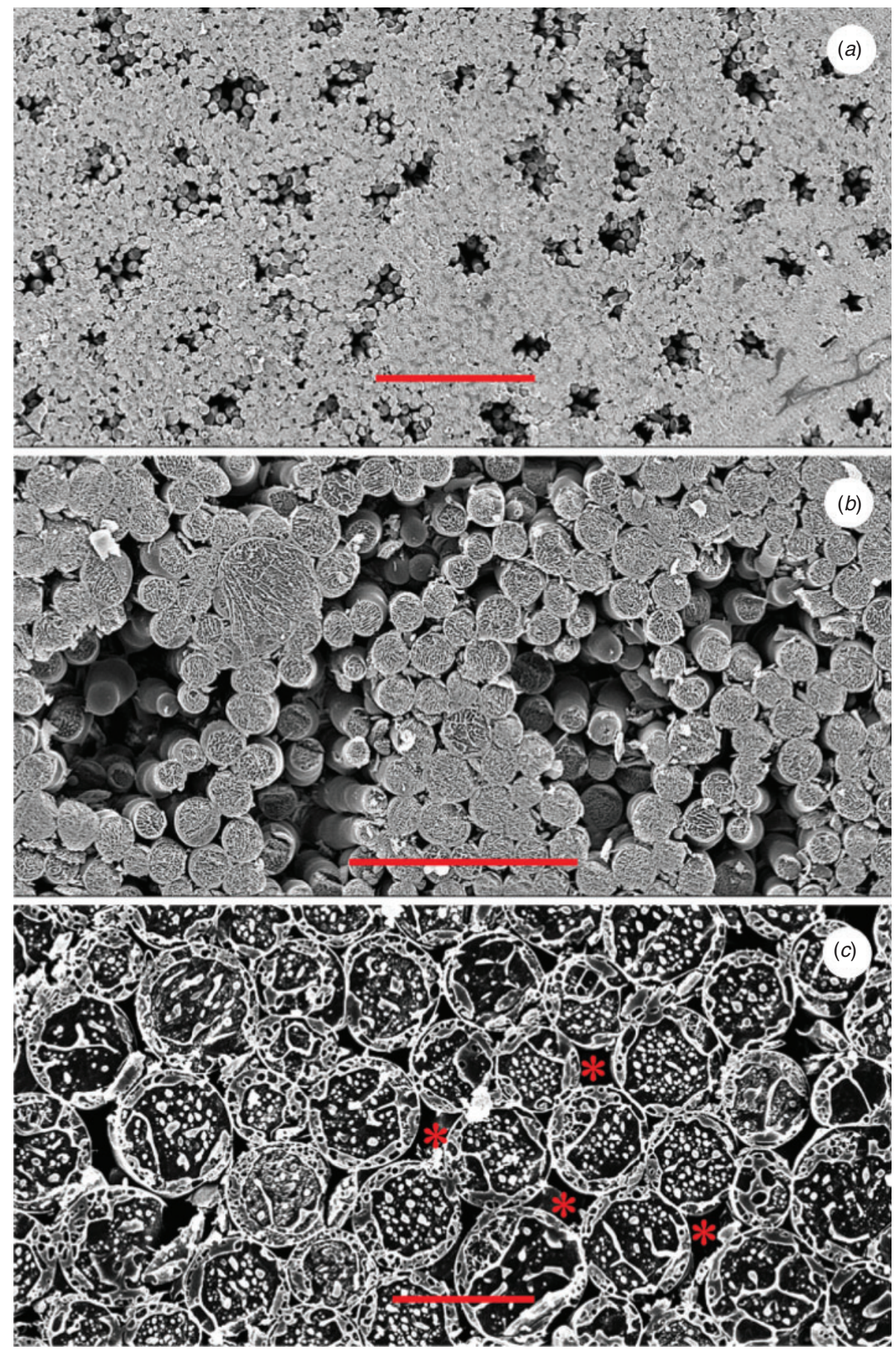

Fig. 2. CSEM faces of cotton leaves planed paradermally. Note the sharp contrasts in the general appearance of different regions. (a) Low resolution image of a planed leaf piece showing the appearance at level $\mathrm{c}-\mathrm{c}$ in Fig. 1a. The 'holes' are sub-stomatal cavities. Scale bar $=200 \mu \mathrm{m}$. (b) Medium resolution image of the cavities, showing separated cells (palisade cavity cells) surrounded by coherent cells (palisade matrix cells). Scale $\mathrm{bar}=100 \mu \mathrm{m}$. (c) Higher resolution image of the coherent tissue at the level $\mathrm{m}-\mathrm{m}$ in Fig. 1a, composed of palisade matrix cells with intercellular spaces (asterisks). Scale bar $=20 \mu \mathrm{m}$. 
$(1 \mu \mathrm{m})$ were stained with toluidine blue $\mathrm{O}$ (Polysciences Inc., Warrington, PA, USA) (0.1\% aqueous, $\mathrm{pH} 11)$. Digital images were processed by Adobe Photoshop CS4 (Adobe Systems Inc., San Jose, CA, USA).

\section{Tissue and cell measurements from Experiments 1 and 2}

The CAF data were not sufficient to describe the changes in cotton leaves, which are more heterogeneous than Eucalyptus leaves. While the Eucalyptus leaves had four layers of palisade mesophyll and no conspicuous substomatal cavities, the cotton leaves had only one layer of palisade mesophyll containing conspicuous cavities, and an equal thickness of spongy mesophyll (Fig. 1 $a, b$ ). Paradermal sections of the palisade mesophyll had two appearances, depending on the depth reached by the planing knife. At the depth indicated by the line $\mathrm{c}-\mathrm{c}$ in Fig. $1 a$, the planed face showed a pattern of 'holes' (Fig. 2a). These proved to be the substomatal cavities. The number of 'holes' per square millimetre in this tissue layer matched the stomatal frequency measured on the adaxial epidermis $\left(\sim 68 \mathrm{~mm}^{-2}\right)$, and in lactic acid-cleared leaves, it was possible to see similar cell arrangements below each stoma. At the depth indicated by the line $\mathrm{m}-\mathrm{m}$ in Fig. $1 a$, the planed face showed a coherent tissue as in Fig. $2 b$, with no 'holes', but small intercellular spaces.

Measurements of the CAF in the tightly packed regions showed no differences between leaves treated over the whole range of $\Delta e(\mathrm{CAF}=0.80-0.89)$. Similar measurements of the area proportion of the 'holes' shown in Fig. $2 a$ (27-33\% of the total area) also showed no response to changing $\Delta e$. It was clear that the separated cells within the cavities were quite different from the coherent cells surrounding the cavities, and showed signs of shrinkage by water loss during transpiration (Fig. $3 a, b$ ).

Thus it was decided to measure the sizes of these two types of cell at each imposed $\Delta e$. They will be distinguished from here on as palisade cavity cells and palisade matrix cells, or cavity cells and matrix cells for short. Regions of each planed face sample were chosen where the mosaic of the two cell types was clear, and measurements were made of the diameters of many cells of each type. A standard magnification of $300 \times$ was chosen as yielding an image that contained a large number of cells but still showed clear details of each cell, and allowed unequivocal placing of the measuring cursor. Examples of measured images are shown in Fig. $4 a, b$. The legend outlines the criteria used to assign cells to their type and to minimise errors. For each imposed $\Delta e$, a total of 500-1200 cells was measured for each tissue type.

\section{Results}

Experiment 1: responses of steady-state mesophyll cells to vapour pressure difference

The response of the mesophyll cells in the steady state to the imposed $\Delta e$ was assessed from the histograms of the measured cell diameters (Fig. 5). The distribution of diameter size was not Gaussian: the s.d. remained the same however many diameters were measured. Nevertheless, the mean diameter was used as typifying the response of the cell type to the $\Delta e$. The numerical comparison is given in Fig. $6 a$. The simple, but unexpected, answer is that the only cells to shrink as $\Delta e$ increases are the cavity cells (diameter shrinking from 17.5 to $\sim 12 \mu \mathrm{m}$ ). The matrix
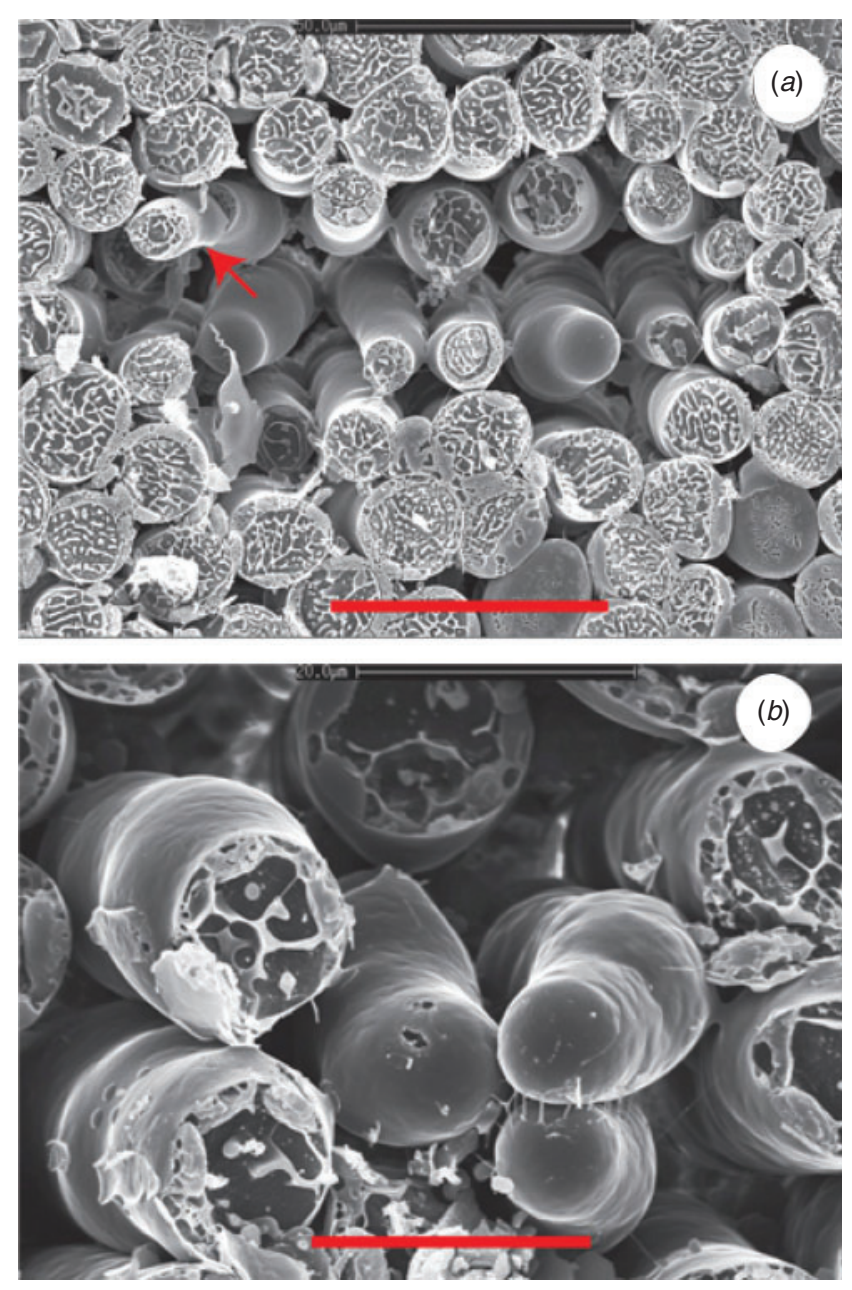

Fig. 3. Paradermal cryo-planed faces of substomatal cavities. (a) Leaf at $\Delta e=1.1 \mathrm{kPa}$. General view of a cavity showing separated cavity cells are surrounded by a coherent tissue of matrix cells (see text). The planing knife has cut all the matrix cells at the same level because they support each other. The cavity cells have little mutual support, and the support of the upper epidermis, to which some were attached, has been removed by the planing. Two cavity cells have rounded tops and were not attached to the epidermis. Several unsupported cavity cells were fractured below the plane of the face by the passage of the knife. Most of the broken pieces have been removed, but one remains on its broken stump (arrow). Scale bar $=50 \mu \mathrm{m}$. (b) Leaf at $\Delta e=1.7 \mathrm{kPa}$. Detail of a few cavity cells with rounded tops that did not reach the upper epidermis and had sparse attachment to neighbour cells. Some cavity cells taper upwards, suggesting shrinkage due to evaporation from the upper zone. Scale bar $=20 \mu \mathrm{m}$.

cells remain unshrunken $(16-19 \mu \mathrm{m})$ over the whole range of $\Delta e$ tested. The rates of transpiration at each imposed $\Delta e$ are given in Fig. 6b. Transpiration increased as $\Delta e$ increased.

\section{Experiment 2: responses of quasi-equilibrated mesophyll cells to relative humidity}

The diameters of the two cell types in leaf disks quasi-equilibrated with different RHs are given in Table 1. As in the transpiring leaf, it is only the cavity cells which respond to changing humidity by losing water. Down to $98 \% \mathrm{RH}$, the cavity cells 

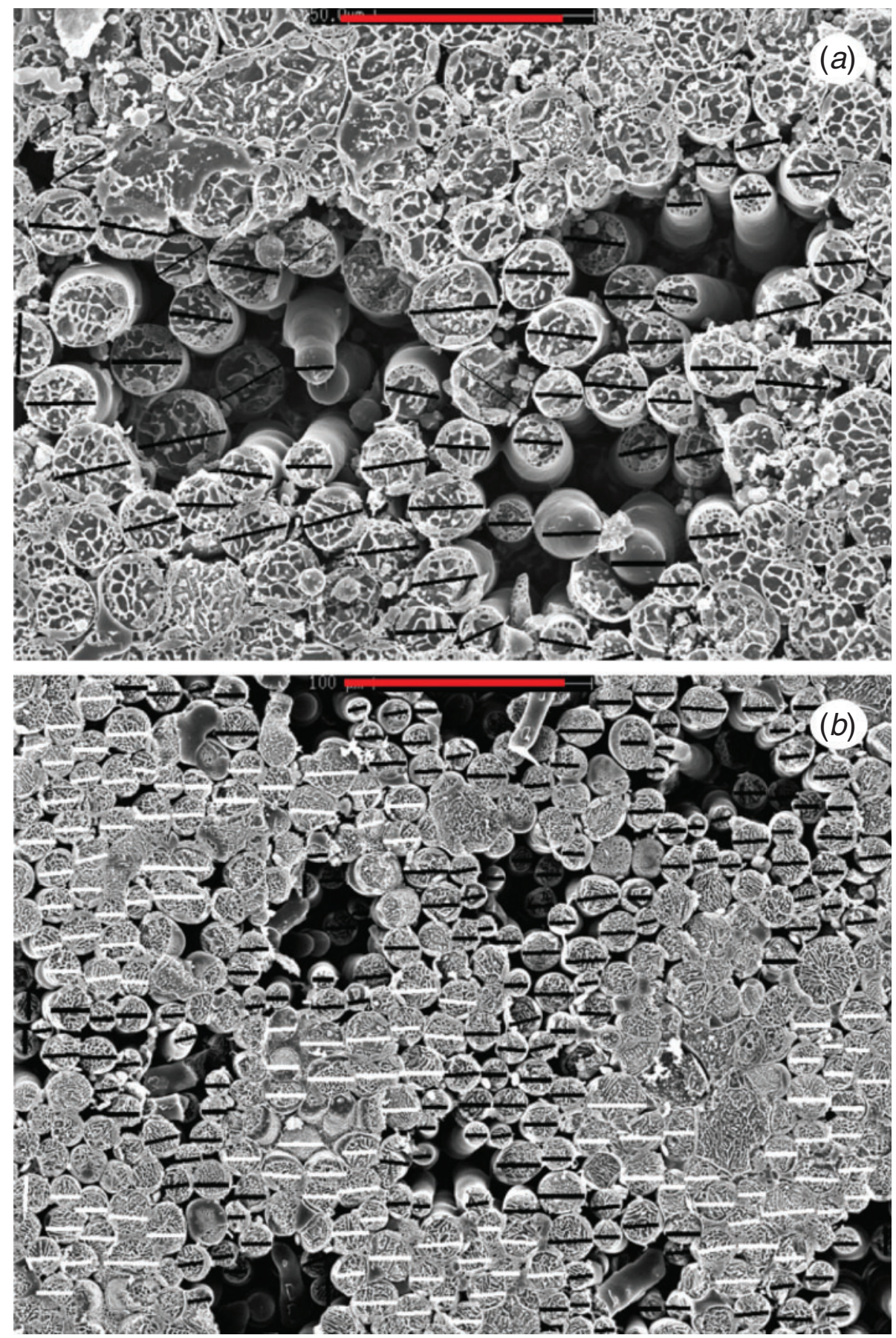

Fig. 4. Measurement of diameters of palisade cells of the two types in cryo-planed paradermal faces. ( $a$ ) Leaf at $\Delta e=1.7 \mathrm{kPa}$. Black lines indicate the diameters of individual cavity cells. Scale bar $=50 \mu \mathrm{m}$. $(b)$ Leaf at $\Delta e=1.1 \mathrm{kPa}$. Selected diameters of cavity cells (black lines) and matrix cells (white lines). The criterion used to distinguish a cavity cell was that more than half its circumference was exposed to the air. To compensate for noncircularity, diameters were measured in the x-direction if possible. Irregular cells (probably bundle sheath cells) like those on the right of $(b)$ were not measured. Not all cells of each type were measured. The measured cell faces at different depths in the cavity (explained in the legend of Fig. 3 and in the text) create an overestimation of the mean cell diameter that would be obtained if all cavity cells were measured at the higher level where many taper upward. (Fig. $3 a, b$ ). Scale bar $=100 \mu \mathrm{m}$. 

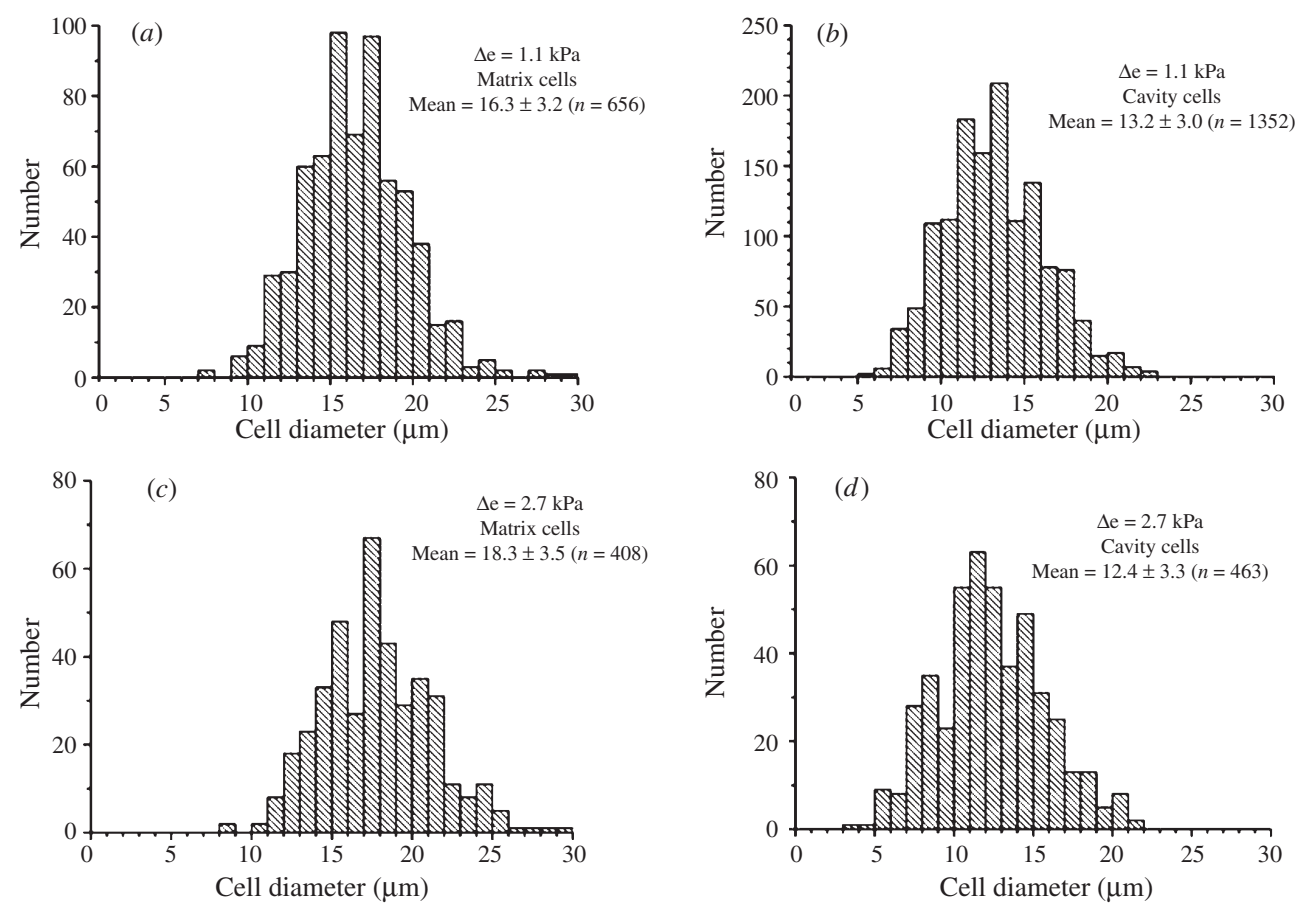

Fig. 5. Selected histograms of measured cell diameters of $(a, c)$ matrix and $(b, d)$ cavity cells at two levels of $\Delta \mathrm{e}:(a, b)$ $\Delta \mathrm{e}=1.1 \mathrm{kPa} ;(c, d) \Delta \mathrm{e}=2.7 \mathrm{kPa}$. The distributions are not strictly Gaussian, but were characterised by the mean and s.d.

did not shrink detectably from their diameter in the saturated leaf, but at $95 \% \mathrm{RH}$, the cavity cells had shrunk by $40 \%$ (Table 1) and distorted (Fig. $7 a$ and inset), leaving few whose diameters could be measured with confidence. The mean of $8.5 \mu \mathrm{m}$ in Table 1 is based on these few. Matrix cells were resistant to shrinking. At $95 \%$, the $\mathrm{RH}$ which almost destroyed the cavity cells, the matrix cells had contracted by $6 \%$ (Table 1) and still formed a coherent cell mass (Fig. 7a). At $92 \% \mathrm{RH}$, all the cells had shrunk and the two types had become unrecognisable, but the cells hung together (Fig. 7b).

The measured RWLs of the quasi-equilibrated leaf disks are plotted in Fig. 8. This graph closely resembles that for the CAF of snow gum leaves as a function of RH in Fig. 8 of Canny and Huang (2006), having a linear regression down to a particular level of RH and a constant value below this RH. By analogy with that result, a dashed horizontal line has been added to intersect the dashed, fitted linear regression of Fig. 8. The solid lines $\mathrm{c}$ and $\mathrm{m}$ show the RWL corresponding to the value of RH from Table 1 at which the diameters of the palisade cavity and matrix cells were unchanged from that in their fully saturated state, viz.: cavity cells, $\mathrm{RH}=98 \%(-2.7 \mathrm{MPa})$ and $\mathrm{RWL}=0.145 ;$ matrix cells $\mathrm{RH}=95 \% \quad(-6.9 \mathrm{MPa})$ and $\mathrm{RWL}=0.4$. Values of water status can be translated approximately to an equivalent balance pressure, $\mathrm{Pb}$. Roderick and Canny (2005) showed that for a range of leaves, $P b$ was a linear function of RWL and that the proportionality constant $\kappa$ was given by their equation 13 :

$$
\kappa=753-763 Q_{\mathrm{x}}
$$

The measured $Q_{\mathrm{x}}$ for cotton leaves was 0.781 (see Methods), so $\kappa=157$ and the RWL for cavity cells of 0.145 translates to
$P b=23$ bar. This is probably an overestimate, as Eqn 1 becomes increasingly unreliable above $\mathrm{RWL}=0.1$ (Roderick and Canny 2005).

The dashed horizontal line in Fig. 8 corresponds to the unchanging volume of the shrunken tissue mass (e.g. Fig. $7 b$ ). The tissues have lost all their unbound, liquid water, and further drying extracts water from the solid solution of cell walls and protoplasts, without further shrinkage.

\section{Cell connections}

Cavity cells show few contacts with each other (Figs 1, 3) and often do not reach to join the adaxial epidermis. Some have rounded tops below the level at which the planing knife has cut through neighbouring cells. In Fig. $9 a, b, 3 \mathrm{D}$ views of contacts between cavity cells are compared with views of their 2D anatomy in a thin optical section. There are clearly two different kinds of contact: those where separate cell walls touch each other, and those where parts of the two cell walls are fused together to make a common wall (primary pit field). The latter kind is also distinguished by an absence of chloroplasts from the parts of the two protoplasts next to the shared fused wall at the pit field. These regions will be distinguished as cell 'interconnections', leaving the term 'contact' for separate cell walls that merely touch. We propose that these interconnections are regions where water and solutes may be most readily exchanged, and predict that they will contain many plasmodesmata.

From images like that in Fig. $7 b$, it is obvious that some junctions between cells are mechanically strong and resistant to breaking under tension. The interconnections as defined above 

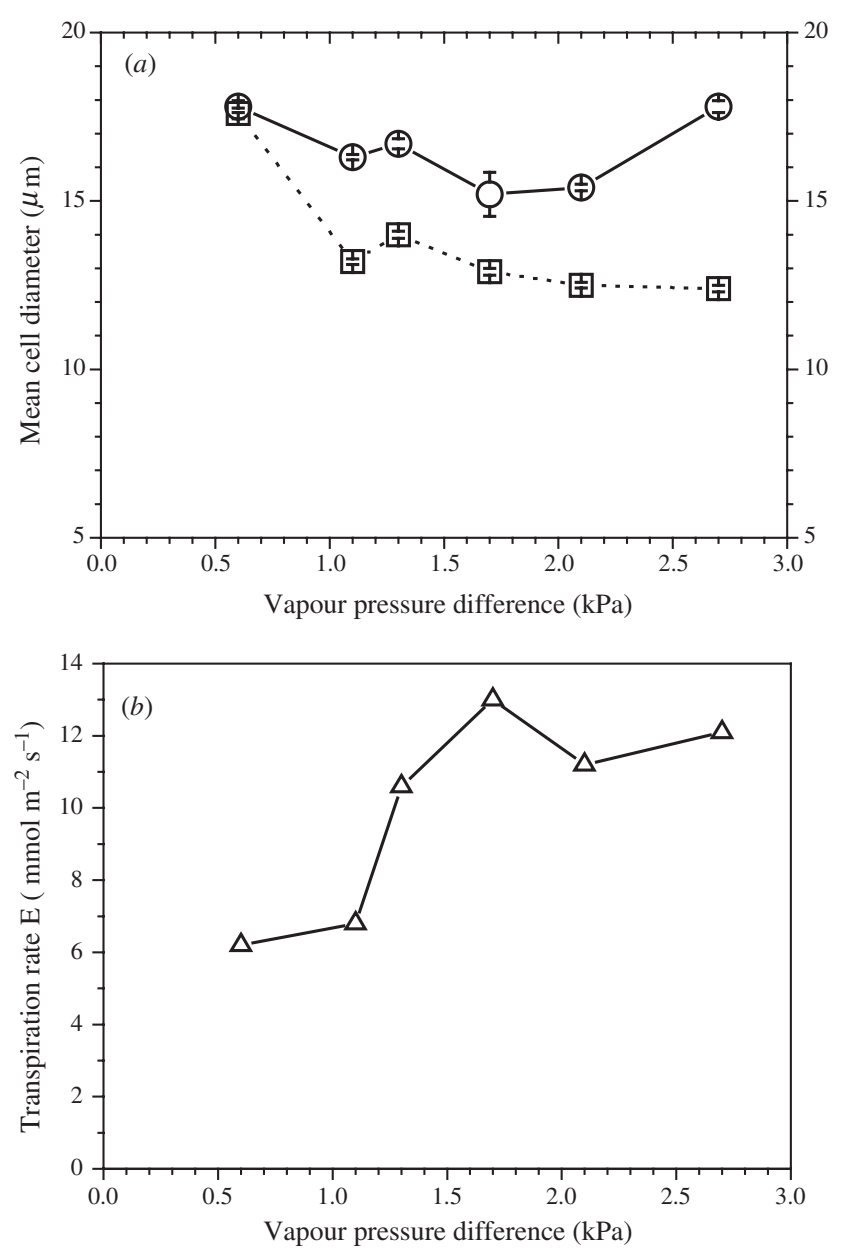

Fig. 6. (a) Summary relation of mean cell diameter to $\Delta e$ for all the experiments. Matrix cells, $\bigcirc-\bigcirc$; cavity cells, $\Delta-\Delta$. Means \pm s.e. (b) Transpiration rates at the imposed levels of $\Delta e$.

Table 1. Responses of cotton leaf-disk mesophyll cells to quasiequilibration with air at different relative humidities (RHs)

\begin{tabular}{lccc}
\hline $\begin{array}{c}\text { Imposed } \\
\text { RH }\end{array}$ & $\begin{array}{c}\text { Osmotic } \\
\text { pressure } \\
(\mathrm{MPa})^{\mathrm{A}}\end{array}$ & $\begin{array}{c}\text { Palisade } \\
\text { cavity } \\
\text { cells }^{\mathrm{B}}\end{array}$ & $\begin{array}{c}\text { Palisade } \\
\text { matrix } \\
\text { cells }^{\mathrm{B}}\end{array}$ \\
\hline $100 \%$ & 0.0 & $14.0 \pm 3.1(631)$ & $16.1 \pm 3.2(320)$ \\
$98 \%$ & 2.7 & $14.7 \pm 3.4(659)$ & $17.7 \pm 3.5(222)$ \\
$95 \%$ & 6.9 & $8.5 \pm 2.5(71)$ & $15.1 \pm 2.6(433)$ \\
\hline
\end{tabular}

${ }^{\mathrm{A}}$ Osmotic pressure of a solution in equilibrium with the $\mathrm{RH}$, calculated as in table 2.1 of Nobel (1970)

${ }^{\mathrm{B}}$ Cell diameters in $\mu \mathrm{m} \pm$ s.d. $(n)$.

could have this additional function of maintaining cell continuity at high relative water loss.

Matrix cells, from their resistance to shrinking, would be expected to have more interconnections, and this is confirmed by images such as Fig. $9 c$. Even so, their interconnections are small in area and much of their surface can make only
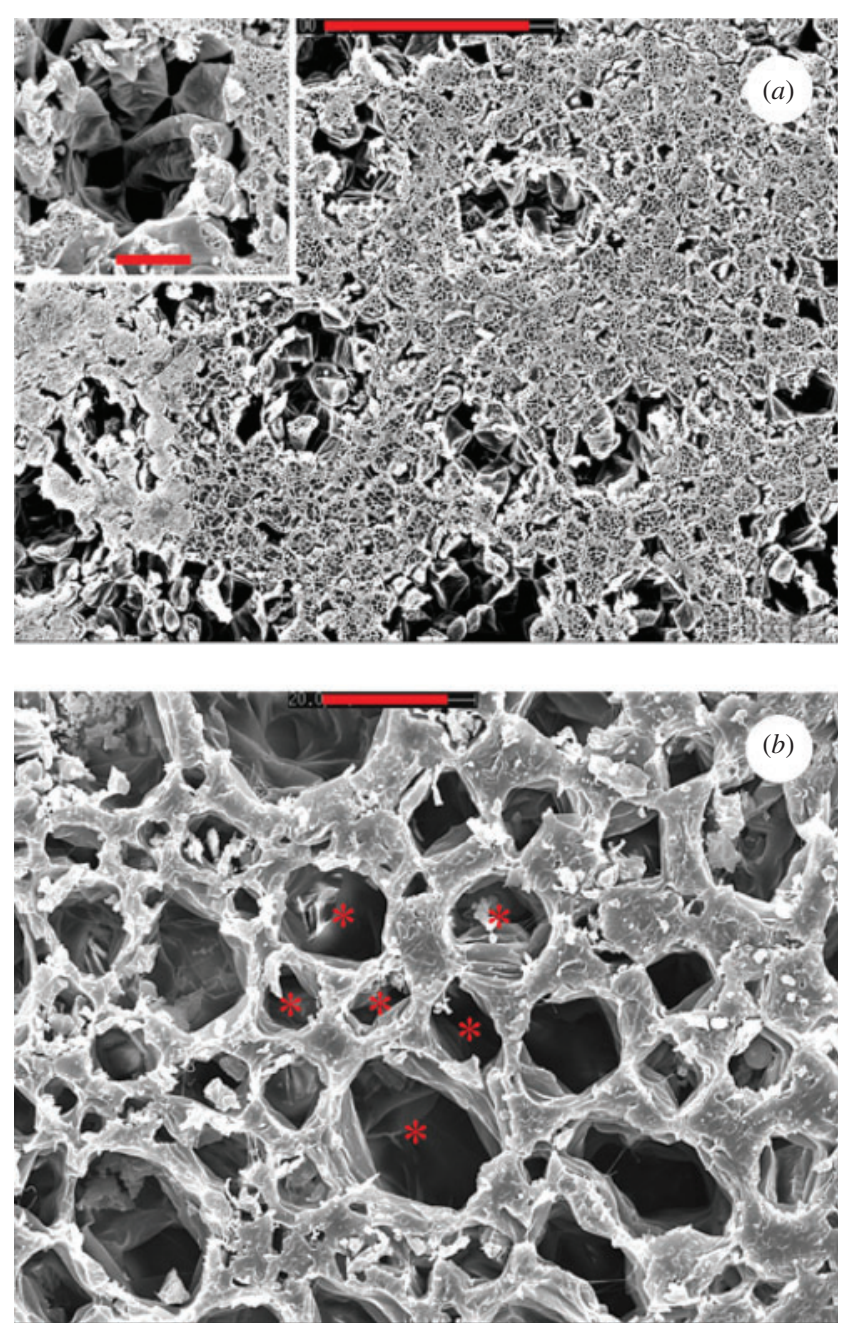

Fig. 7. Cryo-planed faces of quasi-equilibrated cotton mesophyll in leaf disks at (a) 95\% RH and (b) 92\% RH. (a) The cavity cells have shrunk so far as to be almost unrecognisable (inset). The matrix cells have retained nearly their full complement of water (see Table 1). Scale bar $=100 \mu \mathrm{m}$. Inset: Scale bar $=25 \mu \mathrm{m}$. (b) All the cells have collapsed and lost their unbound water at $92 \%$ RH (see Fig. 8). Intercellular spaces (asterisks) are greatly enlarged. Cells remain attached at the places identified as interconnections (Figs 9, 10), demonstrating the strength of the attachments. Scale bar $=20 \mu \mathrm{m}$.

contacts with their neighbours. Again, the interconnections are free of adjacent chloroplasts in the connected cells (Fig. 9d).

In contrast to the small and sparse lateral interconnections of matrix cells, their junctions with the spongy mesophyll cells below are many and wide (Fig. 10a, $b$ ). These junctions are interconnections as defined, and are again places where adjacent chloroplasts are absent in both cells (Fig. 10b). Junctions between spongy mesophyll cells are similarly large and are interconnections as defined (Fig. 1a).

Junctions of both matrix and cavity cells with bundle sheath cells are, like their junctions with spongy mesophyll cells, wide interconnections as defined (arrowheads in Fig. 1a). 


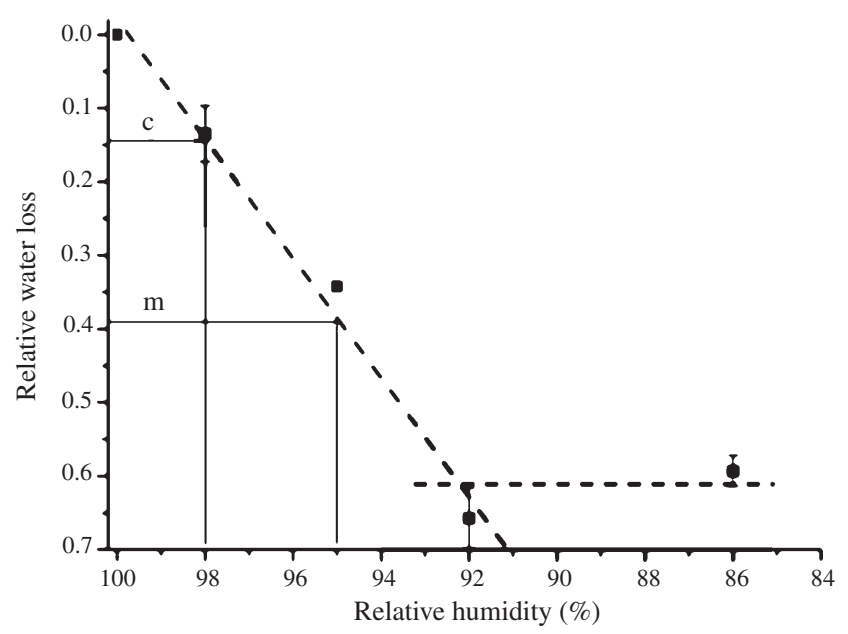

Fig. 8. Water status of cotton leaf disks, expressed as RWL, after quasiequilibration with air of $\mathrm{RH}=100-86 \%$. By $92 \% \mathrm{RH}$, all the unbound water has been removed and the mass does not change further. Continuous lines $c$ and $m$ indicate the RWL at which cavity and matrix cells, respectively, retain their water content overnight at saturation level (see text). Means \pm s.d. The equation of the linear regression is $R W L=8.1-0.081(R H), R^{2}=0.987$

\section{Discussion}

This discussion is arranged as an attempt to use the collected observations in addressing the following question: What are the contributions of the three types of mesophyll cell (palisade matrix, palisade cavity and spongy mesophyll) to the process of transporting water from the veins to the sites of evaporation?

\section{Water compartments: sizes and locations}

From Figs $7 a$ and 8 , it is clear that there are separate compartments of water in the cotton leaf. The measured RWL values enable the estimation of the sizes of these compartments as proportions of the fresh mass $m_{\mathrm{x}}$. The bound water (horizontal line in Fig. 8) is inaccessible. Leaves with RWL $<0.6$ contain available water and the total amount of this is $0.6 m_{\mathrm{x}}$. On the evidence of Fig. $7 a$, this available water is of two kinds: that in the matrix cells, which is not available at RWL $<0.4$ (slow available water), and that in cavity cells, which is available at RWL $>0$ (fast available water). The amount of slow available water is that which can leave the leaf between $\mathrm{RWL}=0.4 m_{\mathrm{x}}$ and RWL $=0.6 m_{\mathrm{x}}$, viz. $0.2 m_{\mathrm{x}}$. The amount of fast available water is the difference between the total available water $\left(0.6 m_{\mathrm{x}}\right)$ and the amount of slow available water $\left(0.2 m_{\mathrm{x}}\right)$, viz. $0.4 m_{\mathrm{x}}$ (Table 2).

The amount of fast available water is clearly much greater than that contained in the cavity cells, and must also be contained in spongy mesophyll cells and possibly also in bundle sheath cells. An approximate allocation of the fast available water to the two cell types can be made. The cavities occupied $\sim 30 \%$ of the palisade mesophyll, so their water content cannot exceed $0.3 \times 0.2 m_{\mathrm{x}}=<0.06 m_{\mathrm{x}}$ (less, because, on the evidence of the images, there is much air space in the cavities). The remainder must be in spongy mesophyll cells and perhaps in bundle sheath cells: $(0.4-0.06) m_{\mathrm{x}}=0.34 m_{\mathrm{x}}$. These allocations are given in Table 2, along with the percentages of the mass of total available water. The two distinct compartments will be referred to as the slow and fast water pools.

\section{Sites of evaporation}

Though it is not a complete proof, the conclusion from Fig. 8 and Table 1 (i.e. in both the steady state and the quasiequilibrium state, the cavity cells shrank with increasing $\Delta e$ but the matrix cells did not) warrants a strong inference that water evaporated from the cavity cells and did not evaporate from the matrix cells. As seen in Fig. 3, cavity cells stand, with very little mutual lateral contact, surrounded by a large volume of air. Many have been cut through by the planing knife and some have broken off at a lower level when dragged by the knife (arrow in Fig. $3 a$ ). Others, with rounded tops, terminate below the level of planing and were not attached to the adaxial epidermis (Fig. 3b). These and the bases of the broken cells are attached to cells at the bottom of the cavity. In summary, the images suggest that water enters these cells from their ends (mostly from below but possibly sometimes above) and evaporates into the air in the cavity.

From the calculations of relative water losses given above, the spongy mesophyll cells must also be a major site of evaporation. They, too, are surrounded by a large volume of air. From the widespread occurrence of leaves that have stomata only on the abaxial surface, they could be regarded as the only site of evaporation in such leaves. Clearly, measurements should be made of their shrinkage during transpiration. The mass of spongy mesophyll cells with cavity cells standing upon them is the functional unit that collects water from the veins and evaporates it to the air spaces. This unit is embedded in another functional unit, a structural unit: the mass of unshrinking matrix cells of constant water status.

\section{Matrix cells}

The most unexpected observation in this study is that a very large proportion of the mesophyll cells in the cotton leaf do not shrink as the leaf loses water down to a RWL $=0.4$ (Fig. 8) and therefore, very probably, water does not evaporate from them. Their connections with their neighbours, though many and strong (Fig. 7b), are limited to a small part of their peripheral walls (Fig. 9c), where there must be primary pit fields and plasmodesmata. From the measured CAF of this tissue, the intercellular spaces around them occupied $10-20 \%$ of the matrix tissue volume. Occasionally some of these spaces contained water.

The highest priority question stimulated by this study is: What property of the matrix cells prevents them from losing water? How, as in Figs $7 a$ and 8, do they stay turgid and with high water content in air of $95 \% \mathrm{RH}$ and at $\mathrm{RWL}=0.4$ (relative water content $=1-0.4 / 0.781=0.49$ ) overnight, when the cavity cells have shrunk so much as to be unrecognisable? Whatever holds the water in becomes ineffective in air of 92\% RH (Fig. 7b). It cannot be osmotic pressure. To balance the free energy of $95 \%$ $\mathrm{RH}$ would require a solution in the vacuoles of osmotic pressure equivalent to $6.9 \mathrm{MPa}$. It might be that their cell walls have cuticles. There have been many reports over the years of the occurrence of cuticles on the walls of mesophyll cells (Scott 

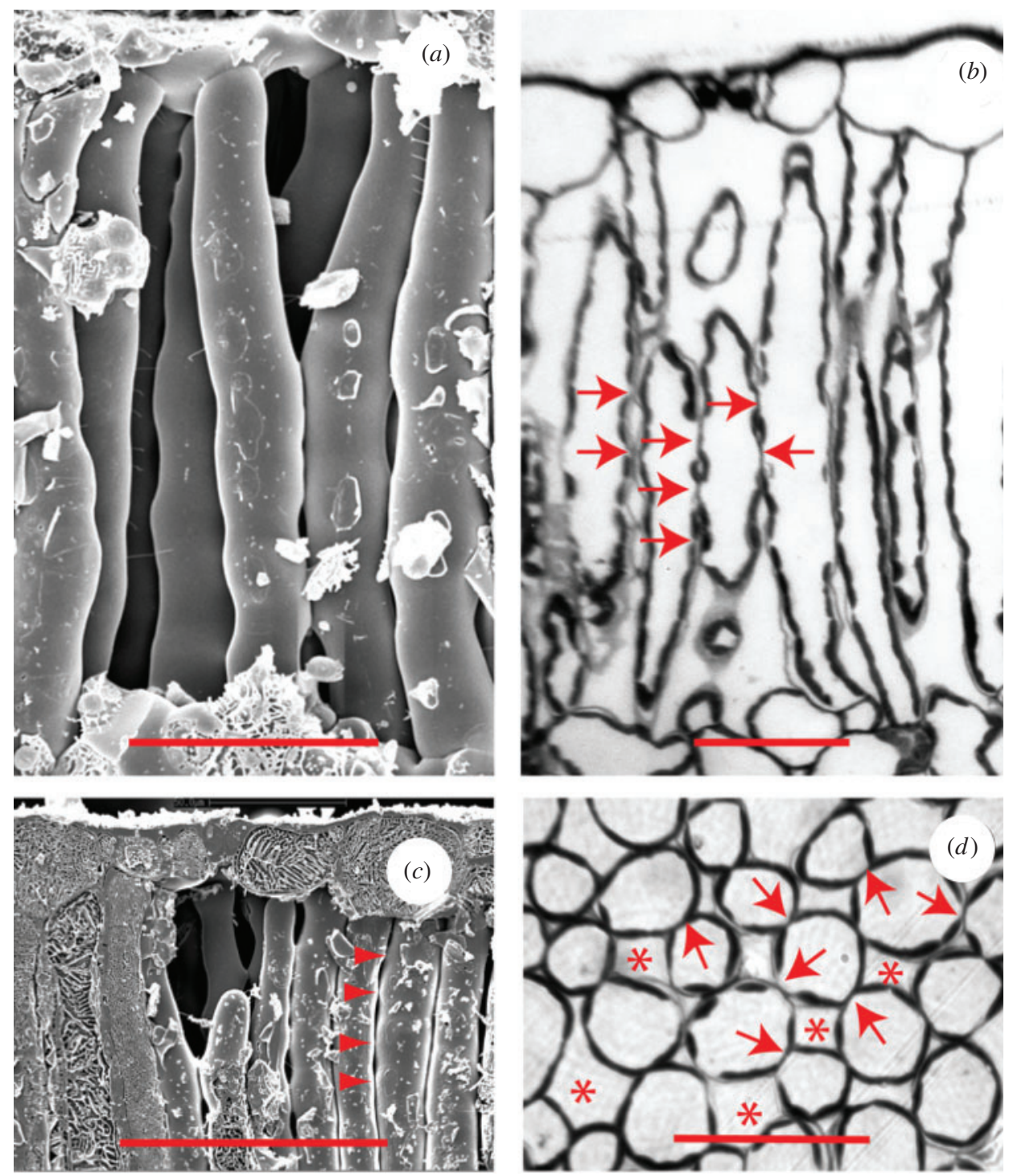

Fig. 9. Cell connections between palisade cells. $(a, b)$ Cavity cells; $(c, d)$ matrix cells. $(a)$ Leaf at $\Delta e=2.7 \mathrm{kPa}$. Cryo-planed transverse faces of cavity cells. Scale bar $=50 \mu \mathrm{m}$. (b) Optical image of cavity cells in a transverse section. Cell interconnections as defined in text (arrows). Chloroplasts are absent at the interconnections. Scale bar $=50 \mu \mathrm{m}$. (c) Leaf at $\Delta e=1.7 \mathrm{kPa}$. Cryo-planed image of cavity cells between two blocks of matrix cells with multiple small interconnections between two matrix cells (arrowheads). Scale bar $=50 \mu \mathrm{m}$. (d) Optical image of matrix cells in a paradermal section. Arrows indicate cell interconnections with an absence of adjacent chloroplasts; asterisks indicate intercellular spaces. Scale bar $=20 \mu \mathrm{m}$.

1950; Schulze 1986; Wullschleger and Oosterhuis 1989; Pesacreta and Hasenstein 1999), but these have focussed more on the cells near to stomata, and on epidermis and guard cells. It may be that the matrix cell walls have a higher elastic modulus than the cavity and spongy cells. (Note that wall elastic moduli are mostly measured in solution. In a transpiring leaf, the cell walls are partly dry, the elastic modulus would be greater (Niklas 1992) and a different method of measurement would be appropriate.)

It would be possible that fully turgid matrix cells were part of the water pathway, and that in the steady state, water flowed through them at various rates but the cells remained fully turgid.
It seems more likely that one of their main functions is structural; that in a leaf with little cell wall material, they are maintained turgid to keep the leaf from wilting, even down to RWL $=0.4$ (Fig. 8). The cotton leaves in Experiment 1 did not wilt at the largest imposed $\Delta e$, but of course cotton leaves do wilt when their water status is low enough. E. pauciflora leaves, with their high content of cell wall structural material, do not wilt.

\section{Water pathway}

The expected path for most of the transpiration water would be from the vessels through the bundle sheath cells to the 

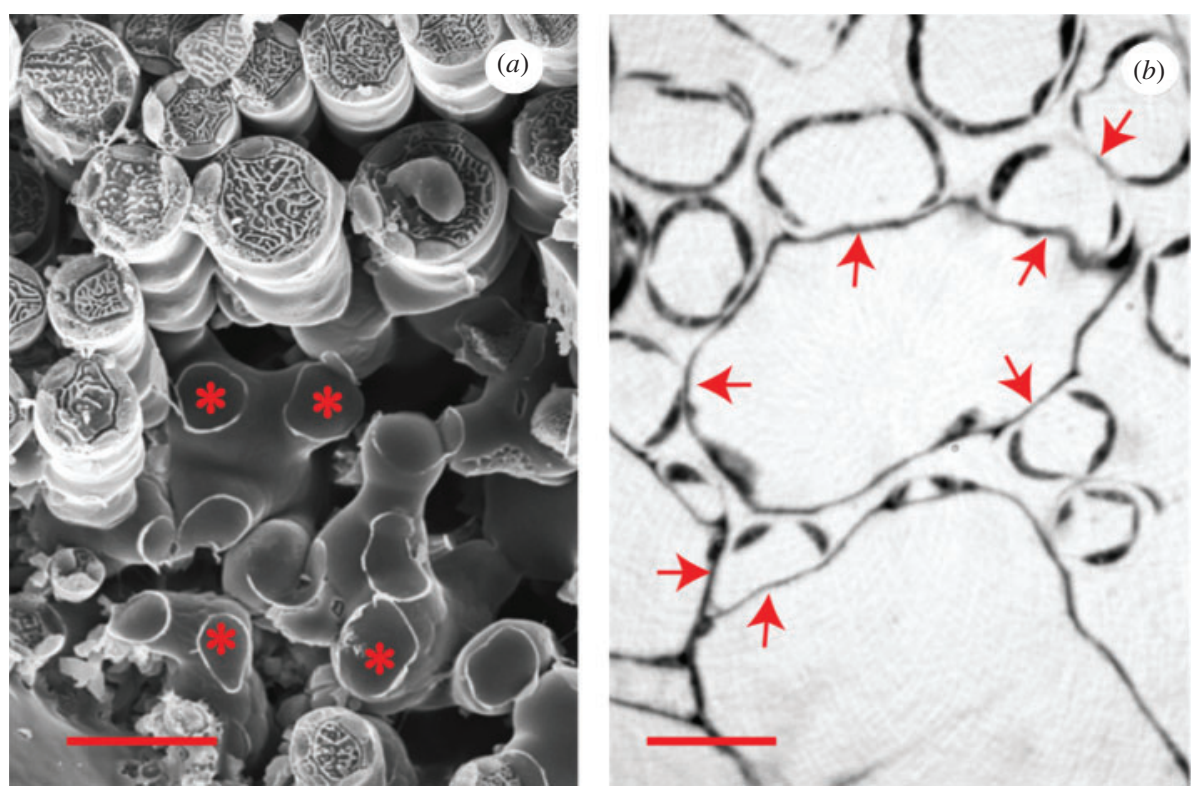

Fig. 10. (a) Face view of the large interconnections (primary pit fields) between palisade mesophyll cells and spongy mesophyll cells (asterisks). CSEM image of fractured leaf at $\Delta e=0.6 \mathrm{kPa}$, showing some matrix cells still attached to the spongy mesophyll, and (below) the interconnections at which the matrix cells have detached. These interconnections are larger in area than those indicated in Fig. $9 c, d$. Scale bar $=25 \mu \mathrm{m}$. (b) Optical image of a paradermal section through the junction of palisade with the spongy mesophyll. The interconnections (arrows) between the small palisade cells (of either type) and the large spongy cells are chloroplast-free. Scale bar $=10 \mu \mathrm{m}$.

Table 2. Masses (relative to the saturated mass $m_{\mathrm{x}}$ ), and proportions (\%) of water pools deduced from Fig. 8

\begin{tabular}{lccc}
\hline Water pool & $\begin{array}{c}\text { Proportions } \\
\text { of } m_{\mathrm{x}}\end{array}$ & $\begin{array}{c}\text { Mesophyll } \\
\text { cell type }\end{array}$ & $\begin{array}{c}\text { \% of available } \\
\text { water }\end{array}$ \\
\hline Total available water & 0.6 & All mesophyll & 100 \\
Slow available water & 0.2 & Matrix & 33 \\
Fast available water & 0.4 & Cavity + spongy & 67 \\
& $<0.06$ & Cavity & $<1$ \\
& $>0.34$ & Spongy & $>66$ \\
\hline
\end{tabular}

spongy mesophyll, where it would evaporate to the intercellular air and pass through abaxial stomata to the external air. But from the spongy mesophyll, it could also move directly through the wide interconnections at the base of the cavity cells to evaporate into the air within the cavity and through the adaxial stomata to the external air. The matrix cells can be supplied with abundant water through their large interconnections to the spongy cells, but this functional unit is more of a static reservoir than a part of the pathway. Lateral movement between matrix cells towards the cavities is probably a small proportion of the water traffic because of the minimal area of the interconnections. All matrix cells are attached to the upper epidermis, which could form another part of the pathway, as in wheat (Triticum aestivum L.) leaves (Fig. 6c of Canny 1990), but its volume proportion is a small part of the leaf cell volume, and it is removed from the source in the xylem.

\section{Water pools}

Separate compartments of water were inferred by Yakir et al. (1989, 1990) from the evidence of isotopic equilibrations of deuterium and oxygen-18 in leaves of sunflower and ivy (Yakir et al. 1989) and in cotton (Yakir et al. 1990). On the basis of the speeds of equilibration from fastest to slowest, they identified three compartments of water in veins, cell walls and symplasm, with relative volumes of $3 \%, 22 \%$ and $75 \%$ in ivy; and $1 \%, 32 \%$ and $67 \%$ in sunflower. In the paper on cotton, they again identified three similar compartments but did not estimate their relative sizes.

Our results with cotton leaves again identify three tissue compartments, but allocate them to different tissue components and two categories of equilibration times (Table 2). The spongy mesophyll cells and cavity cells respond quickly to losses or gains of leaf water (fast equilibration times). The matrix cells respond much more slowly to such changes (slow equilibration times). These two pools of water may be compared with the two pools of water found in four mesophytic angiosperm trees by Zwieniecki et al. (2007), studying the rehydration kinetics of leaves dried to $\mathrm{RWL}=\sim 0.1$ and supplied with water through the cut petiole. The time constants of the two pools were: fast pool, 100-200 s; slow pool, 3000-5000 s. The size of the fast pool was 55-70\% of the volume of water absorbed, which, for a leaf with (assumed) $Q_{\mathrm{x}}=0.7$, translates to $38-49 \%$ of leaf mass. This fits well with the estimated size of the fast pool in cotton: $40 \%$ of leaf mass (above). Similarly, the single fast pool found by Zwieniecki et al. (2007) in Eucalyptus globulus Labill. agrees 
with the single pool found by Canny and Huang (2006) in Eucalyptus pauciflora. On the basis of these three approaches to how quickly the water pools turn over, we suggest that the pools be distinguished as dynamic and static pools.

We hypothesise that there is a real distinction between sclerophytic and mesophytic leaves in their manner of maintaining rigidity, and that leaves of other mesophytic angiosperms may be found to have palisade matrix cells that contribute structural rigidity by maintaining turgor while water is lost from spongy mesophyll and cavity cells.

\section{Recovery of turgor}

The Eucalyptus study of Canny and Huang (2006) concluded with a discussion of Levitt's finding that a detached, wilted cabbage (Brassica oleracea L.) leaf, which had lost 25-30\% of its water, regained turgor and stiffness without taking up any water (Levitt 1986). This phenomenon was confirmed and further investigated by Weisz et al. (1989).

It is now possible to offer an explanation for this phenomenon. If, like cotton, cabbage has the palisade mesophyll separated into cavity cells and matrix cells, then it, too, may support the rigidity of its leaves by maintaining unshrunken matrix cells. Then a detached, wilted leaf with depleted matrix cells could regain its rigidity by redistributing water from the cavity cells and spongy mesophyll, and restoring matrix cells to full turgor. The suggestion could be tested in CSEM preparations of wilted and recovered leaves. The mechanism that would allow accumulation of water in matrix cells at the expense of the rest of the mesophyll is, like the maintenance of different water statuses in the mesophyll of cotton, mysterious.

The mere fact of such recovery is surely evidence of the existence of two pools of water in a cabbage leaf. Weisz et al. indeed investigated the possibility, referred to above, that there might be cell walls in the mesophyll with different elastic moduli. They found no evidence of this, but they used the pressure-volume curve method, and so measured the elastic moduli of wet cell walls, not partly dry ones, which may have higher moduli.

\section{Acknowledgements}

We thank Marilyn Ball for the provision of facilities, and Graham Farquhar, Margaret McCully, Paul Kriedemann, John Passioura and Michael Roderick for helpful advice on presentation.

\section{References}

Canny MJ (1990) What becomes of the transpiration stream? New Phytologist 114, 341-368. doi:10.1111/j.1469-8137.1990.tb00404.x

Canny MJ (1995) Apoplastic water and solute movement: new rules for an old space. Annual Review of Plant Physiology and Plant Molecular Biology 46, 215-236. doi:10.1146/annurev.pp.46.060195.001243
Canny MJ, Huang CX (2006) Leaf water content and palisade cell size. New Phytologist 170, 75-85. doi:10.1111/j.1469-8137.2005.01633.x

Levitt J (1986) Recovery of turgor by wilted, excised cabbage leaves in the absence of water uptake. Plant Physiology 82, 147-153. doi:10.1104/ pp.82.1.147

McCully ME, Canny MJ (2011) Cryo-SEM and cryoanalytical-SEM for plant biology (Online). In: PrometheusWiki: Online Protocols in Ecological and Environmental Physiology. Available at http:// prometheuswiki.publish.csiro.au/tiki-custom_home.php [posted 11 March 2011; verified 18 November 2011]

McCully ME, Canny MJ, Huang CX (2009) Cryo-scanning electron microscopy (CSEM) in the advancement of functional plant biology. Morphological and anatomical applications. Functional Plant Biology 36, 97-124. doi:10.1071/FP08304

McCully ME, Canny MJ, Huang CX, Miller C, Brink F (2010) Cryo-scanning electron microscopy (CSEM) in the advancement of functional plant biology: energy dispersive X-ray microanalysis (CEDX) applications. Functional Plant Biology 37, 1011-1040. doi:10.1071/FP10095

Niklas K (1992) 'Plant biomechanics.' (The University of Chicago Press: Chicago)

Nobel PS (1970) 'Physicochemical and environmental plant physiology' (Academic Press: New York)

Pesacreta TC, Hasenstein KH (1999) The internal cuticle of Cirsium horridulum (Asteraceae) leaves. American Journal of Botany 86, 923-928. doi: $10.2307 / 2656608$

Roderick ML, Canny MJ (2005) A mechanical interpretation of pressure chamber measurements - what does the strength of the squeeze tell us? Plant Physiology and Biochemistry 43, 323-336. doi:10.1016/j. plaphy.2005.02.014

Schulze E-D (1986) Carbon dioxide and water vapour exchange in response to drought in the atmosphere and in the soil. Annual Review of Plant Physiology 37, 247-274. doi:10.1146/annurev.pp.37.060186.001335

Scott FM (1950) Internal suberization of tissues. Botanical Gazette (Chicago, Ill.) 111, 378-394. doi:10.1086/335610

Stamm AJ (1964) 'Wood and cellulose science.' (Ronald Press: New York)

Weisz PR, Randall HC, Sinclair TR (1989) Water relations of turgor recovery and restiffening of wilted cabbage leaves in the absence of water uptake. Plant Physiology 91, 433-439. doi:10.1104/pp.91.1.433

Wullschleger SD, Oosterhuis DM (1989) The occurrence of an internal cuticle in cotton (Gossypium hirsutum L.) leaf stomates. Environmental and Experimental Botany 29, 229-235. doi:10.1016/0098-8472(89)90054-3

Yakir D, DeNiro MJ, Rundel PW (1989) Isotopic inhomogeneity of leaf water: evidence and implications for the use of isotopic signals transduced in plants. Geochimica et Cosmochimica Acta 53, 2769-2773. doi:10.1016/ 0016-7037(89)90147-6

Yakir D, DeNiro MJ, Gat JR (1990) Natural deuterium, and oxygen-18 enrichment in leaf water of cotton plants grown under wet and dry conditions: evidence for water compartmentation and its dynamics. Plant, Cell \& Environment 13, 49-56. doi:10.1111/j.1365-3040.1990. tb01298.x

Zwieniecki MA, Brodribb TJ, Holbrook NM (2007) Hydraulic design of leaves: insights from rehydration kinetics. Plant, Cell \& Environment 30, 910-921. doi:10.1111/j.1365-3040.2007.001681.x 